\title{
PENGARUH AKUNTABILITAS, PENGETAHUAN, DAN PENGALAMAN TERHADAP KUALITAS HASIL KERJA AUDITOR PADA INSPEKTORAT KABUPATEN MAMASA PROVINSI SULAWESI BARAT
}

\author{
Sumarni $\mathbf{S}^{(1)}$ dan Baso $\mathbf{R}^{(2)}$ \\ (Sekolah Tinggi Ilmu Ekonomi Wira Bhakti Makassar) \\ basoranungkalobe@gmail.com
}

\begin{abstract}
ABSTRAK
Penelitian ini bertujuan untuk menganalisa secara empiris pengaruh akuntabilitas, pengetahuan, dan pengalaman terhadap kualitas pekerjaan auditor. Penelitian ini dilakukan di kabupaten Mamasa dengan responden auditor dan staf yang bekerja di kantor inspektorat kabupaten Mamasa di provinsi sulawesi barat. Sampel dilakukan dengan teknik purposive judgment sampling. Data dikumpulkan menggunakan kuesioner yang didistribusikan sebanyak 40 dan hanya 36 kuesioner yang dapat diproses. Analisis data menggunakan analisis regresi linier berganda. Hasil penelitian menunjukkan bahwa akuntabilitas, pengetahuan, dan pengalaman memiliki pengaruh positif terhadap kualitas pekerjaan auditor.
\end{abstract}

Keywords: akuntabilitas, pengetahuan, pengalaman, kualitas pekerjaan auditor

\section{PENDAHULUAN}

Laporan keuangan perlu diaudit oleh Kantor Akuntan Publik (KAP) dengan dua alasan yaitu 1) jika tidak diaudit ada kemungkinan bahwa laporan keuangan tersebut mengandung kesalahan baik yang disengaja maupun yang tidak disengaja sehingga diragukan kewajarannya oleh pihakpihak yang berkepentingan terhadap laporan keuangan dan 2) jika laporan keuangan sudah diaudit dan mendapat opini wajar tanpa pengecualian (Unqualified Opinion) dari KAP, berarti laporan keuangan tersebut dapat diasumsikan bebas dari salah saji material dan telah disajikan sesuai dengan Standar Akuntansi Keuangan (SAK) yang berlaku umum di Indonesia.(Agoes .2004)

Audit merupakan suatu proses untuk mengurangi ketidakselarasan informasi yang terjadi antara manajemen dan stekholder, sehingga 
inspektorat harus semakin materil dalam mengaudit laporan keuangan. Jasa audit merupakan jasa yang sering digunakan oleh pihak yang berkepentingan untuk menilai perusahaan dan mengambil keputusan. Dari hasil audit inilah, kemudian auditor menarik sebuah simpulan dan menyampaikan simpulan tersebut kepada stekholder yang berkepentingan (Mardisar dan Sari, 2007).

Kualitas dari hasil pekerjaan auditor dapat dipengaruhi oleh rasa kebertanggungjawaban (akuntabilitas), pengetahun dan pengalaman yang dimiliki auditor dalam menyelesaikan pekerjaan audit (Mardisar dan Sari, 2007). Profesi auditor dipercaya oleh klien untuk dapat membuktikan kewajaran laporan keuangan yang disajikan kliennya Untuk terus mendapat kepercayaan dari kliennya dan pengguna laporan keuangan, maka seorang auditor dituntut untuk menjadi seorang yang memiliki kompetensi (Cris Kuntandi, 2019) auditor ketika mengaudit harus memiliki keahlian yang meliputi pengetahuan, keterampilan dan sikap perilaku yang diperlukan dalam pelaksanaan tugas jabatannya. Menurut Komite SPAP Ikatan Akuntan Indonesia (IAI), (2001) Pencapaian keahlian dimulai dengan pendidikan formal, selanjutnya melalui pengalaman dan praktek audit.

Sesuai dengan standar umum dalam Standar Profesional inspektorat maka auditor disyaratkan memiliki pengalaman kerja yang cukup dalam profesi yang ditekuninya, serta dituntut untuk memenuhi kualifikasi teknis dan berpengalaman dalam instansi yang mereka audit atau dengan kata lain bahwa auditor harus memiliki kompetensi (Cris Kuntandi, 2019). Penelitian ini mengkonfirmasi penelitian dari Mardisar dan Sari (2007) yang membahas tentang pengaruh akuntabilitas dan pengetahuan terhadap kualitas hasil kerja auditor.

Penelitian ini bertujuan untuk menguji pengaruh Akuntabilitas, Pengetahuan dan Pengalaman terhadap kualitas audit. Ketiga faktor tersebut paling dominan dan dalam kenyataannya sering menjadi masalah bagi akuntan publik, klien maupun pihak ketiga pengguna laporan keuangan klien. Penelitian (Mardisar Sari, 20107) menemukan bahwa akuntabilitas berpengaruh signifikan terhadap kualitas audit. Penelitian ini sejalan dengan 
penelitian (Ariviana Bella, 2014; Laksita AD,2019; dan Sanjaya KS, dkk, 2019. Hasil penelitian berbeda diungkapkan oleh (Suspayati, R.S, dkk 2019) yang menunjukkan akuntabilitas auditor tidak berpengaruh pada kualitas proses audit.

Fenomena lainnya yang juga mampu mempengaruhi kualitas audit yaitu pengetahuan auditor, penelitian terkait hal tersebut dilakukan (Mardisar Sari, 2007; Indah, 2010; Queena PP,2012; Ariviana Bella,2014; Putri PP, 2015; Rahayu dkk, 2016; Suspayati, R.S, dkk 2019) yang menunjukkan bukti bahwa pengetahuan audit berpengaruh terhadap kualitas audit. Hasil berbeda ditunjukkan (Mahadi Suriani AR dkk,2019 dan Sihombing YA dkk, 2019) yang menemukan bahwa pengetahuan auditor tidak berpengaruh terhadap kualitas audit. Sedangkan pengaruh pengalaman auditor terhadap kualitas audit telah diteliti oleh Mardisar Sari, 2007; Indah, 2010; Praditiningrum AC, 2012; Ariviana Bella, 2014 Rahayu T dkk, 2016; Mahdi Suriana AR dkk, 2019) hasil berbeda ditemukan oleh Queena PP, 2012; Putri FP, 2015 dan Sihombing YA dkk, 2019 bahwa pengalaman tidak berpangaruh terhadap kualitas audit. Berdasarkan uraian tersebut, penulis bermaksud melakukan penelitian lebih lanjut untuk menjawab permasalahan yaitu apakah variabel akuntabilitas, variabel pengetahuan dan variabel pengalaman auditor berpengaruh positif terhadap kualitas audit pada Inspektorat Kabupaten Mamasa Provinsi Sulawesi Barat ?.

\section{TINJAUAN PUSTAKA}

\section{Teori Agensi (Agency Theory)}

Menurut Jensen dan Meckling (1976), Teori Keagenan (Agency Theory) menjelaskan hubungan antara agen (manajemen) suatu instansi pemerintah dengan prinsipal. Prinsipal disebut sebagai pihak yang melakukan evaluasi terhadap informasi sedangkan agen adalah pihak yang mengambil keputusan. Di dalam hubungan keagenan (agency relationship) terdapat suatu kontrak dimana satu orang atau lebih (yaitu prinsipal) memerintah orang lain (yaitu agen) untuk melakukan suatu jasa 
atas nama prinsipal dan memberi wewenang kepada agen untuk membuat keputusan yang terbaik bagi prinsipal.

Teori agensi merupakan hubungan kontrak antara prinsipal dan agen selaku pelaku utama dalam perusahaan (Arifin, 2005). Teori keagenan memiliki tujuan utama yaitu apabila terdapat masalah yang dikarenakan oleh beberapa pihak yang saling bekerja sama namun memiliki tujuan berbeda, maka masalah keagenan yang terjadi akan terjawab dengan teori keagenan. Untuk mengurangi atau meminimalkan kecurangan yang dilakukan oleh manajemen dan membuat laporan keuangan yang dibuat manajemen lebih reliabel (dapat dipercaya) diperlukan pengujian.

Pengujian ini dilakukan oleh pihak yang independen, yaitu auditor independen (Indah, 2010). Dengan adanya auditor yang independen diharapkan tidak terjadi kecurangan dalam laporan keuangan yang dibuat oleh manajemen. Sekaligus dapat mengevaluasi kinerja agen (manajer) sehingga akan menghasilkan informasi relevan yang berguna bagi investor dan kreditor dalam mengambil keputusan rasional untuk investasi (Hidayat, 2011). Auditor yang kredibel dapat memberikan informasi yang lebih baik kepada pengguna informasi, karena dapat mengurangi asimetris informasi antara pihak manajemen dengan pihak pemilik (Indah, 2010).

\section{Kualitas Hasil Kerja Auditor}

Menurut Agoes S. (2018:4) menyatakan bahwa audit adalah suatu pemeriksaan yang dilakukan secara kritis dan sistematis oleh pihak yang independen terhadap laporan yang telah disusun oleh manajemen, beserta catatan-catatan pembukuan dan bukti-bukti pendukung nya dengan tujuan untuk dapat memberi kan pendapat mengenai kewajaran laporan keuangan tersebut.

Kualitas hasil kerja berhubungan dengan seberapa baik sebuah pekerjaan diselesaikan dibandingkan dengan kriteria yang telah ditetapkan. Untuk auditor, menurut Queena, P. P., \& Rohman, A. (2012) menyatakan bahwa obyektivitas, pengetahuan, integritas, etika, skeptisisme profesional auditor berpengaruh positif dan signifikan terhadap kualitas audit. Lebih 
lanjut Laksita, A. D., \& Sukirno, S. (2019) menyatakan bahwa Independensi, Akuntabilitas, Objektivitas, berpengaruh terhadap kualitas Audit.

Kualitas audit pada penelitian Singgih dan Bawono (2010) menggunakan empat indikator yaitu : budaya dalam institut audit, keahlian dan kualitas personal audit, efektivitas proses audit, keandalan dan manfaat laporan audit.

\section{Akuntabilitas}

Pada penelitian Alvita (2010:55) terdapat enam faktor yang mempengaruhi sikap akuntabilitas individu sebagai berikut: 1) Latar belakang (background factors, 2) Keyakinan perilaku atau behavioral belief 3) Keyakinan normatif (normatif belief), 4) Norma subjektif (subjective norm), 5) Keyakinan bahwa suatu perilaku dapat dilaksanakan (control belief) diperoleh dari berbagai hal, 6) Perilaku kemampuan mengontrol (perceived behavioral control. Indikator Akuntabilitas Pada penelitian Feny dan Yohanes (2012) yaitu 1. Motivasi, 2) Kewajiban Sosial 3) Pengabdian pada profesi. Auditor menjalankan pekerjaan auditor dan laporan audit sesuai dengan SAP dan SPAP dengan bertanggungjawab serta tidak memanipulasi hasil audit.

Robbins (2008 : 222) dalam Singgih dan Bawono (2010) mendefinisikan motivasi (motivation) sebagai proses yang menjelaskan intensitas, arah, dan ketekunan seorang individu untuk mencapai tujuannya. Akuntabilitas pada penelitian Singgih dan Bawono (2010) menggunakan tiga indikator yaitu : motivasi, pengabdian pada profesi, dan kewajiban sosial. Yang juga akan peneliti gunakan dalam penelitian ini.

\section{Pengetahuan}

Sucipto (2007) mendefinisikan pengetahuan menurut ruang lingkup audit adalah kemampuan penguasaan auditor atau stekholder pemeriksa terhadap medan audit (penganalisaan terhadap laporan keuangan pemerintah). Variabel pengetahuan akan diukur dengan menggunakan indikator pengetahuan umum yang dimiliki auditor dalam menjalankan profesinya.

\section{Pengalaman}

Pengalaman merupakan suatu proses pembelajaran dan 
pertambahan perkembangan potensi bertingkah laku (Singgih dkk, 2010). Pengalaman dapat memberikan peluang bagi seseorang untuk melakukan pekerjaan dengan lebih baik (Praditaningrum, 2012). Seorang auditor yang berpengalaman akan semakin peka dalam memahami setiap informasi yang relevan sehubungan dengan judgment yang akan diambilnya.

\section{Pengambangan Hipotesis}

Hipotesis ini dirumuskan berdasarkan penelitian dari Mardisar dan Sari (2007) yang membahas tentang pengaruh akuntabilitas dan pengetahuan terhadap kualitas hasil kerja auditor. Hal ini sejalan dengan (Ariviana Bella, 2014; Laksita AD,2019; dan Sanjaya KS, dkk, 2019) menyimpulkan bahwa secara parsial akuntabilitas auditor berpengaruh secara positif terhadap kualitas audit. Hal yang berbeda dari hasil penelitian oleh Suspayati, R.S, dkk 2019 menyimpulkan bahwa akuntabilitas tidak berpengaruh positif terhadap kualitas audit.

$\mathrm{H}_{1}$ : Akuntabilitas berpengaruh positif terhadap kualitas hasil kerja auditor.

Pengetahuan auditor berpengaruh terhadap kualitas audit telah diteliti

oleh (Mardisar Sari, 2007; Indah, 2010; Queena PP,2012; Ariviana Bella,2014; Putri PP, 2015; Rahayu dkk, 2016; Suspayati, R.S, dkk 2019). Namun hasil berbeda ditemukan oleh (Mahadi Suriani AR dkk,2019 dan Sihombing YA dkk, 2019) bahwa pengetahuan tidak berpengaruh terhadap kualitas audit.

$\mathrm{H}_{2}$ : Pengetahuan berpengaruh positif terhadap kualitas hasil kerja auditor.

Pengalaman auditor berpengaruh terhadap kualitas audit diteliti oleh Mardisar Sari, 2007; Indah, 2010; Praditiningrum AC, 2012; Ariviana Bella, 2014 Rahayu T dkk, 2016; Mahdi Suriana AR dkk, 2019) tapi hasil berbeda ditemukan oleh Queena PP, 2012; Putri FP, 2015 dan Sihombing YA dkk, 2019 bahwa pengalaman auditor tidak berpengaruh terhadap kualitas audit. H3 : pengalaman berpengaruh positif terhadap kualitas hasil kerja auditor 


\section{METODOLOGI PENELITIAN}

Penelitian ini termasuk dalam kategori penelitian kausal dengan menggunakan metode kuantitatif. Metode penelitian yang digunakan dalam penelitian ini menggunakan metode analisis kuantitatif sebab data yang digunakan merupakan data empiris dan variabel yang digunakan mempunyai satuan yang dapat diukur. Tekhnik pengambilan sampel yang dilakukan dengan dengan menggunakan metode pendekatan Purposive sampling untuk menentukan sampel dari populasi yang memenuhi kriteria untuk menjawab permasalahan penelitian. Hal ini dilakukan agar jawaban kusisioner dapat terjawab dengan baik pada subjek yang tepat dan berkompeten dibidangnya.

Sampel yang diambil adalah staf/pejabat pemeriksa dan auditor yang bekerja pada Inspektorat di kota Mamasa dengan karakteristik anggota populasi yang dijadikan sampel : 1). Auditor yang bekerja inspektorat khususnya di Kabupaten mamasa, 2). Bersedia menjadi responden dalam penelitian. 3). Memiliki latar belakang pendidikan minimal SI Akuntansi. Adapun bentuk dari kuesioner yang digunakan dalam penelitian ini adalah kuesioner tertutup. Peneliti mengukur jawaban kuesioner menggunakan skala likert lima poin. Skala likert adalah sebuah jawaban dimana responden diminta untuk memberikan pernyataan setuju atau tidak setuju (Sekaran, 2011). Semakin tinggi nomor jumlah, maka semakin besar variabel independen mempengaruhi variabel dependen.

\section{Definisi Operasional Variabel}

Pada penelitian ini menggunakan kualitas audit $(Y)$ sebagai variabel dependen dan akuntabilitas (X1), Pengetahun (X2) Pengelamanan (X3) sebagai variabel independen.

Kualitas hasil kerja auditor ini merupakan variabel yang tidak bisa diukur secara langsung melainkan menggunakan indikator lainnya seperti akuntabilitas, pengetahuan, pengalaman, dan independensi. Pengertian kualitas hasil kerja auditor yaitu sikap auditor dalam melaksanakan tugasnya yang tercermin dalam hasil pemeriksaannya dan dapat diandalkan sesuai dengan standar yang berlaku. Kualitas hasil kerja auditor diukur 
dengan menggunakan kuesioner sebanyak 16 item pertanyaan yang menggunakan 5 poin skala likert.

\section{Akuntabilitas}

Akuntabilitas secara umum artinya permintaan pertanggungjawaban atas pemenuhan tanggung jawab yang diserahkan kepadanya. Variabel akuntabilitas diukur menggunakan indikator pertanyaan yang dikembangkan oleh Kalbers dan Forgaty (1995), telah diterjemahkan dan dimodifikasi oleh Aji (2009 : 51-52) dalam Singgih dan Bawono (2010) yaitu : motivasi, pengabdian pada profesi, dan kewajiban sosial. Dengan 13 item pertanyaan yang dinilai dengan menggunakan 5 poin skala likert.

\section{Pengetahuan}

Pengetahuan merupakan sebuah pemahaman yang dimiliki oleh seorang auditor yang didapatkan dari SAK dan SPAP mengenai pemahaman akan jenis dan kondisi perusahaan yang menjadi kliennya. Variabel pengetahuan diukur dengan indikator pengetahuan umum seperti yang dikembangkan Harhinto (2004). Dengan 5 item pertanyaan yang dinilai dengan menggunakan 5 poin skala likert.

\section{Pengalaman}

Pengalaman adalah keterampilan dan pengetahuan yang diperoleh seseorang setelah mengerjakan suatu hal. Variabel pengalaman akan diukur dengan menggunakan indikator lamanya bekerja, frekuensi pekerjaan pemeriksaan yang telah dilakukan, seperti yang digunakan oleh Aji (2009) serta ditambah dengan satu indikator yang juga dapat memproksikan pengalaman seorang auditor yaitu banyaknya pelatihan yang telah diikutinya, yang diambil dari aspek-aspek kompetensi yang dikembangkan oleh Mansur (2007) dan telah direplikasi oleh Rahman (2009) dalam Singgih dan Bawono (2010). Dengan 7 item pertanyaan yang dinilai dengan menggunakan 5 poin skala likert.

\section{HASIL PENELITIAN DAN PEMBAHASAN}

\section{Hasil Penelitian}

\section{Deskripsi Hasil Penelitian}

Data penelitian yang digunakan dalam penelitian ini merupakan data 
primer yang diperoleh dengan menggunakan daftar pertanyaan (kuesioner) yang telah disebarkan melalui contact person kepada aparat Inspektorat Kabupaten Mamasa Provinsi Sulawesi Barat pada tanggal 13 Juli 2019. Sampai dengan batas akhir pengembalian yakni tanggal 30 Juli 2019, dari 38 kuisioner yang disebarkan, 40 kuisioner yang kembali dan 3 kuisioner yang tidak kembali. Tingkat pengembalian (response rate) yang diperoleh adalah 92,1 \% sedangkan sisanya 7,9 \% tidak kembali. Hal ini dikarenakan adanya pegawai yang cuti dan dinas keluar kota pada saat penyebaran kuisioner dilakukan, akibatnya perantara tidak sempat memberikan kuesioner sampai batas waktu yang ditentukan.

Data demografi responden ini menyajikan beberapa informasi umum mengenai kondisi responden yang ditemukan di lapangan. antara lain jenis kelamin, Umur, status, pendidikan dan pengalaman kerja. Dari daftar pertanyaan yang dibagikan, menunjukan bahwa auditor yang terdapat di Inspektorat Kabupaten Mamasa Provinsi Sulawesi Barat. diketahui bahwa responden (aparat) perempuan lebih banyak yaitu 62,5\% dibandingkan responden laki-laki yang hanya $37,5 \%$. Selanjutnya responden dikelompokkan berdasarkan usia dan diketahui bahwa mayoritas responden berusia $36-45$ tahun yaitu sebanyak $50 \%$. Kemudian mereka yang berusia kurang dari 26-30 tahun sebanyak 22,5\%. Dan mereka yang berusia $46-$ 56 tahun sebanyak $27,5 \%$. Adapun mereka yang bersatus kawin sebanyak 39 orang $(97.5 \%)$ dan yang tidak kawin sebanyak 1 orang $(2.5 \%)$. Sedangkan mereka mayoritas berpendidikan S1 yaitu sebanyak 34 orang (85\%), selanjutnya yang berpendidikan D3 sebanyak 5 Orang (12.5\%) dan mereka yang berpendidikan S2 adalah sebanyak 1 orang $(2.5 \%)$. Selanjutnya mereka mayoritas telah bekerja selama 1-10 Tahun yaitu 28 (70\%), mereka yang telah bekerja 11-10 tahun sebanyak 8 orang (20\%) dan mereka yang telah bekerja 21-30 tahun adalah sebanyak 4 orang (10\%).

\section{Uji Validitas}

Hasil uji validitas yang dilakukan dengan bantuan program SPSS versi 20,0 menunjukkan bahwa hasil uji hitung lebih besar dari pada $r$ tabel untuk setiap item butir pernyataan dengan skor total variabel kualitas hasil 
kerja Auditor (Y), Akuntabilitas (X1), Pengetahuan (X2), dan pengalaman (X3). Dengan demikian dapat diinterpretasikan bahwa setiap item indikator instrumen untuk kualitas hasil kerja auditor.

Tabel 1. Uji Validitas Akuntabilitas Auditor (X1)

\begin{tabular}{|r|c|c|c|}
\hline No & R hitung & R tabel & Keterangan \\
\hline 1 & 0.813 & & Valid \\
2 & 0.353 & & Valid \\
3 & 0.705 & & Valid \\
4 & 0.754 & & Valid \\
5 & 0.586 & Valid \\
6 & 0.338 & Valid \\
7 & 0.493 & & Valid \\
8 & 0.603 & Valid \\
9 & 0.813 & Valid \\
10 & 0.353 & Valid \\
11 & 0.705 & & Valid \\
12 & 0.754 & Valid \\
13 & 0.586 & Valid \\
14 & 0.338 & Valid \\
15 & 0.429 & Valid \\
16 & 0.738 & Valid \\
17 & 0.813 & Valid \\
18 & 0.353 & & Valid \\
\hline Sumber : data diolah, 2019 & & \\
\hline
\end{tabular}

Tabel 1 menggambarkan uji validitas variabel akuntabilitas auditor. Terlihat bahwa $r$ hitung lebih besar di bandingkan dengan $r$ tabel, sehingga dapat disimpulkan bahwa setiap item pertanyaan variabel akuntabilitas auditor adalah valid.

Tabel 2. Uji Validitas Pengetahuan Auditor (X2)

\begin{tabular}{|c|c|c|c|}
\hline No & $\mathbf{R}_{\text {hitung }}$ & $\mathbf{R}_{\text {Tabel }}$ & Keterangan \\
\hline 1 & 0.718 & & Valid \\
2 & 0.858 & & Valid \\
3 & 0.528 & & Valid \\
4 & 0.823 & & Valid \\
5 & 0.553 & 0.3120 & Valid \\
6 & 0.699 & & Valid \\
7 & 0.727 & & Valid \\
8 & 0.708 & Valid \\
9 & 0.718 & & Valid \\
10 & 0.858 & & Valid \\
\hline
\end{tabular}

Sumber : data diolah, 2019

Tabel 2 menggambarkan uji validitas variabel pengetahuan auditor. Terlihat bahwa $r$ hitung lebih besar dibandingkan dengan $r$ tabel, sehingga 
disimpulkan bahwa setiap item pertanyaan variabel pengetahuan auditor adalah valid.

Tabel 3. Uji Validitas Pengalaman Kerja (X3)

\begin{tabular}{|r|c|c|c|}
\hline No & R hitung & R Tabel & Keterangan \\
\hline 1 & 0.401 & & Valid \\
2 & 0.690 & & Valid \\
3 & 0.633 & & Valid \\
4 & 0.875 & 0.3120 & Valid \\
5 & 0.697 & & Valid \\
6 & 0.820 & & Valid \\
7 & 0.597 & & Valid \\
8 & 0.918 & & Valid \\
\hline
\end{tabular}

Tabel 3 menggambarkan uji validitas variabel pengalaman kerja. Terlihat bahwa $r$ hitung lebih besar dibandingkan dengan $r$ tabel, sehingga dapat disimpulkan bahwa setiap item pertanyaan variabel pengetahuan auditor adalah valid.

Tabel 4. Uji Validitas Kualitas Kerja Auditor (Y)

\begin{tabular}{|r|r|c|c|}
\hline \multicolumn{1}{|c|}{ No } & R hitung & R Tabel & Keterangan \\
\hline 1 & 0.764 & & Valid \\
2 & 0.586 & & Valid \\
3 & 0.610 & & Valid \\
4 & 0.615 & & Valid \\
5 & 0.652 & 0.3120 & Valid \\
6 & 0.736 & & Valid \\
7 & 0.624 & & Valid \\
8 & 0.487 & & Valid \\
9. & 0.764 & & Valid \\
10. & 0.586 & & Valid \\
\hline
\end{tabular}

Sumber : data diolah, 2019

Tabel 4 menggambarkan uji validitas variabel pengalaman kerja. Terlihat bahwa $r$ hitung lebih besar dibandingkan dengan $r$ tabel, sehingga dapat disimpulkan bahwa setiap item pertanyaan variabel pengetahuan auditor adalah valid.

\section{Uji Reliabilitas}

Hasil perhitungan uji reliabilitas menunjukkan bahwa nilai Cronbach Alpha ( $\alpha$ ) untuk masing-masing variabel adalah lebih besar dari 0,60, dengan demikian dapat disimpulkan bahwa item-item instrumen untuk masingmasing variabel adalah reliabel (Nunnally dalam Ghozali, 2006). 
Tabel 5. Hasil Uji Reliabilitas

\begin{tabular}{|c|c|c|}
\hline Variabel & $\begin{array}{c}\text { Cronbach's Alpha Based on } \\
\text { Standardized Items }\end{array}$ & Keterangan \\
\hline Akuntabilitas Auditor & 0,748 & Reliabel \\
\hline Pengetahuan Auditor & 0,772 & Reliabel \\
\hline Pengalaman kerja & 0,779 & Reliabel \\
\hline Kualitas kerja Auditor & 0,754 & Reliabel \\
\hline
\end{tabular}

Sumber : data diolah, 2019

\section{Uji normalitas}

Uji normalitas disajikan pada tabel 6 berikut ini.

Tabel 6. Hasil uji normalitas

\section{One-Sample Kolmogorov-Smirnov Test}

\begin{tabular}{|ll|r|}
\hline & \multicolumn{1}{|c|}{ Unstandardized Residual } \\
\hline Normal & Mean & 40 \\
Parameters & Std. Deviation & $0 \mathrm{E}-7$ \\
Most Extreme & Absolute & .16158958 \\
Differences & Positive & .093 \\
Kolmogorov-Smirnotive & .060 \\
Asymp. Sig. (2-tailed) & -.093 \\
\hline
\end{tabular}

a. Test distribution is Normal.

b. Calculated from data.

Sumber : data diolah, 2019

Hasil uji normalitas pada Tabel 6 memberikan gambaran bahwa sebaran data tidak menunjukkan penyimpangan dari kurva normalnya, yang berarti bahwa sebaran data telah memenuhi asumsi normalitas. grafik normal P-plot. Dimana dasar pengambilan keputusan menurut Ghozali (2018).

Gambar 2. Grafik Normal P-P Plot

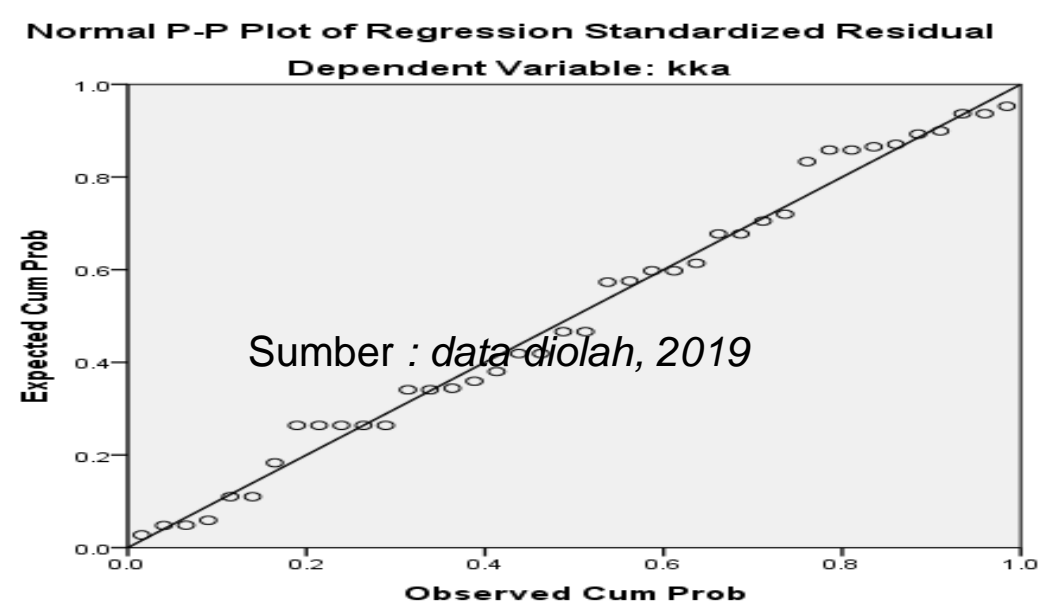


Dengan melihat tampilan pada grafik normal P-Plot terlihat titik-titik menyebar disekitar garis diagonal, serta arah penyebarannya mengikuti arah garis diagonal. menunjukkan model regresi layak dipakai karena memenuhi asumsi normalitas.

\section{Uji Multikolinieritas}

Hasil uji multikolinieritas dapat dilihat tabel 7 berikut:

Tabel 7. Hasil Uji Mulikolinearitas

\begin{tabular}{|l|c|c|c|}
\hline \multirow{2}{*}{$\begin{array}{c}\text { Variabel } \\
\text { Independen }\end{array}$} & \multicolumn{2}{|c|}{ Collinearity Statistics } & \multirow{2}{*}{ Keputusan } \\
\cline { 2 - 3 } & Tolerance & VIF & Tidak ada multikolinearitas \\
\hline $\begin{array}{l}\text { Akuntabilitas } \\
\text { Auditor }\end{array}$ & 0.156 & 6.391 & \\
\hline $\begin{array}{l}\text { Pengetahuan } \\
\text { auditor }\end{array}$ & 0.420 & 2.387 & Tidak ada multikolinearitas \\
\hline Pengalaman kerja & 0.470 & 2.145 & Tidak ada multikolinearitas \\
\hline
\end{tabular}

Sumber : data diolah, 2019

Berdasarkan Tabel 7 di atas dapat disimpulkan dalam model regresi tidak terjadi multikolinieritas antar variabel independen tersebut.

\section{Uji Heterokedastisitas}

Uji heteroskedastisitas menggunakan metode grafik plot Regression Standarized Predicted Value dengan Regression Studentized Residual. Hasil pengujian dapat dilihat pada gambar 3 berikut ini :

\section{Gambar 3. Grafik Scatterplot}

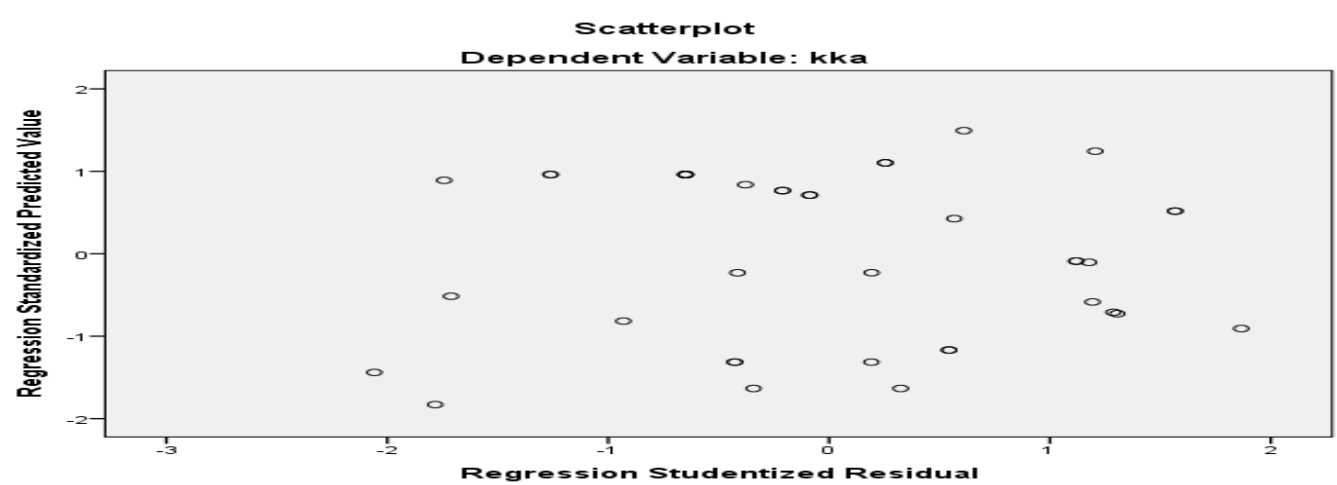

Sumber : data diolah, 2019

Berdasarkan grafik scatterplot di atas mengindikasikan bahwa tidak terjadi heteroskedastisitas dalam model regresi.

\section{Analisis Regresi Berganda}

Berikut ini adalah uraian hasil pengujian regresi berganda dan output table pengujian dengan menggunakan bantuan program SPSS versi 20,0 
dalam bentuk output model summary, ANOVA (uji F), serta coefficient (uji t) sebagai berikut:

\section{Uji Koefisien Determinasi}

Berdasarkan tampilan output model summary pada tabel 8 , besarnya adjusted $\mathrm{R}^{2}$ (koefisien determinasi yang telah disesuaikan) adalah 0,825. Nilai ini menunjukkan bahwa $82,5 \%$ variasi kualitas auditor dapat dijelaskan oleh variasi dari ketiga variabel independen yaitu Akuntabilitas, pengetahuan, dan pengalaman sedangkan sisanya $17,5 \%$ dijelaskan oleh sebab lain di luar model.

Tabel 8. Hasil Uji Koefisien Determinasi

\section{Model Summary}

\begin{tabular}{|l|c|r|r|r|}
\hline $\begin{array}{l}\text { Mo } \\
\text { del }\end{array}$ & $R$ & R Square & Adjusted R Square & Std. Error of the Estimate \\
\hline 1 & $.916^{\mathrm{a}}$ & .838 & .825 & .16819 \\
\hline
\end{tabular}

a. Predictors: (Constant), pk, aa, pa

Sumber : data diolah, 2019

\section{Uji Simultan (Uji F)}

Dari hasil pengujian terhadap uji simultan ANOVA atau Ftest seperti yang ditampilkan pada tabel 9 dibawah ini diperoleh nilai Fhitung sebesar 62,236 dengan probabilitas 0,000 . Karena probabilitas jauh lebih kecil dari nilai signifikan 0,05, maka model regresi dapat digunakan untuk memprediksi kualitas hasil kerja auditor atau dapat dikatakan bahwa Akuntabilitas, pengetahuan dan pengalaman aparat Inspektorat secara simultan berpengaruh terhadap kualitas auditor.

Tabel 9. Hasil Uji Simultan (Uji F) ANOVAa

\begin{tabular}{|l|r|r|r|r|l|}
\hline Model & Sum of Squares & Df & Mean Square & F & Sig. \\
\hline Reg. & 5.281 & 3 & 1.760 & 62.236 & $.000^{\mathrm{b}}$ \\
Residual & 1.018 & 36 & .028 & & \\
Total & 6.300 & 39 & & & \\
\hline
\end{tabular}

a. Dependent Variabel: kka

b. Predictors: (Constant), pk, aa, pa

Sumber : data diolah, 2019

Secara lebih tepat, nilai Fhitung dibandingkan dengan Ftabel dimana jika Fhitung > Ftabel maka secara simultan variabel-variabel independen berpengaruh signifikan terhadap variabel dependen. Pada taraf $\alpha=0,05$ dengan derajat kebebasan pembilang/df1 $(\mathrm{k})=3$ (jumlah variabel independen) dan derajat kebebasan penyebut/df2 $(n-k-1)=36$, diperoleh 
nilai Ftabel 2,99. Dengan demikian, nilai Fhitung 62,236 lebih besar dari nilai Ftabel (2,999). Berdasarkan hasil perhitungan tersebut dapat diinterpretasikan bahwa variabel Akuntabilitas, pengetahuan dan pengalaman aparat Inspektorat secara simultan berpengaruh terhadap kualitas auditor

\section{Uji Parsial}

Hasil pengujian hipotesis pertama $(\mathrm{H} 1)$ yang menyebutkan bahwa Akuntabilitas auditor aparat ispekteorat berpengaruh positif terhadap kualitas auditor dikonfirmasi pada tabel 10. Tabel 10 tersebut menunjukkan bahwa nilai koefisien regresi variabel akuntabilitas auditor aparat inspektorat (X1) adalah 1,293 dan nilai thitung 7,999. Nilai koefisien regresi ini signifikan pada tingkat signifikansi 0,05 dengan $p$ value sebesar 0,000.

\section{Tabel 10. Hasil Uji Parsial (Uji T)}

\begin{tabular}{|c|c|c|c|c|c|}
\hline \multirow[t]{2}{*}{ Model } & \multicolumn{2}{|c|}{ Unstandardized Coefficients } & \multirow{2}{*}{$\begin{array}{c}\text { Standardized } \\
\text { Coefficients } \\
\text { Beta }\end{array}$} & \multirow[t]{2}{*}{$\mathrm{T}$} & \multirow[t]{2}{*}{ Sig. } \\
\hline & B & Std. Error & & & \\
\hline Constant) & .089 & .317 & & .282 & .780 \\
\hline $\mathrm{X} 1$ & 1.293 & .162 & 1.355 & 7.999 & .000 \\
\hline $\mathrm{X} 2$ & .527 & .251 & .686 & 2.094 & .043 \\
\hline X3 & -.839 & .210 & -1.241 & -4.000 & .000 \\
\hline
\end{tabular}

Sumber : data diolah, 2019

\section{Pembahasan}

Hasil pengujian hipotesis pertama $(\mathrm{H} 1)$ yang menyebutkan bahwa Akuntabilitas berpengaruh positif terhadap kualitas hasil kerja auditor. Hasil ini dipertegas dengan hasil perhitungan nilai $t_{\text {hitung }}$ dan $t_{\text {tabel. }}$. Nilai $t_{\text {tabel }}$ pada taraf signifikansi 5\% dan df (derajat kebebasan) n-k-1 = 36 adalah 1,697. Dengan demikian, nilai $t_{\text {hitung }} 7,999>t_{\text {tabel }}$ 1,697. Hasil pengujian ini menginterpretasikan bahwa variabel akuntabilitas auditor aparat inspektorat berpengaruh positif dan signifikan terhadap kualitas audit pada taraf signifikansi $5 \%$ atau dengan kata lain $\mathrm{H} 1$ diterima.

Hasil pengujian hipotesis kedua $\left(\mathrm{H}_{2}\right)$ yang menyebutkan bahwa pengetahuan auditor aparat inspektorat berpengaruh positif terhadap kualitas audit dikonfirmasi pada tabel 10. Ditunjukkan bahwa nilai koefisien regresi variabel pengetahuan aparat inspektorat (X2) adalah 0,527 dan nilai thitung 
2,094. Nilai koefisien regresi ini signifikan pada tingkat signifikansi 0,05 dengan $p$ value sebesar 0,043 . Hasil ini menjelaskan bahwa nilai koefisien regresi variabel pengetahuan auditor aparat Inspektorat (X2) berpengaruh positif dan signifikan terhadap kualitas auditor

Hasil ini diperkuat dengan hasil perhitungan nilai $t_{\text {hitung }}$ dan $t_{\text {tabel }}$. Nilai $t_{\text {tabel }}$ pada taraf signifikansi 5\% dan df (derajat kebebasan) $n-k-1=36$ adalah 1,697. Dengan demikian, nilai thitung 2,094 > 1,697 sehingga perubahan atau variasi variabel pengetahuan auditor akan diikuti oleh variasi kualitas auditor. Berdasarkan hasil pengujian $\mathrm{H} 2$ ini dapat diinterpretasikan bahwa variabel pengetahuan auditor aparat inspektorat berpengaruh positif dan signifikan terhadap kualitas auditor pada taraf signifikansi $5 \%$ atau dengan kata lain $\mathrm{H} 2$ diterima.

Hasil pengujian hipotesis kedua $(\mathrm{H} 2)$ yang menyebutkan bahwa pengetahuan auditor aparat inspektorat berpengaruh positif terhadap kualitas auditor dikonfirmasi pada tabel 10. Ditunjukkan bahwa nilai koefisien regresi variabel pengalaman kerja aparat inspektorat (X3) adalah -0.839 dan nilai thitung $-4,000$. Nilai koefisien regresi ini signifikan pada tingkat signifikansi 0,05 dengan $p$ value sebesar 0,000 . Hasil ini menjelaskan bahwa nilai koefisien regresi variabel pengalaman kerja aparat Inspektorat (X3) berpengaruh negatif namun signifikan terhadap kualitas auditor

Hasil pengujian hipotesis ketiga $(\mathrm{H} 3)$ pengalaman berpengaruh positif terhadap kualitas hasil kerja auditor. Hasil ini diperkuat dengan hasil perhitungan nilai $t_{\text {hitung }}$ dan $t_{\text {tabel }}$. Nilai $t_{\text {tabel }}$ pada taraf signifikansi $5 \%$ dan df (derajat kebebasan) $n-k-1=36$ adalah 1,697. Dengan demikian, nilai $t_{\text {hitung }}$ 2,094 > 1,697 sehingga perubahan atau variasi variabel pengalaman kerja auditor akan diikuti oleh variasi kualitas auditor. Berdasarkan hasil pengujian $\mathrm{H}_{3}$ ini dapat diinterpretasikan bahwa variabel pengalaman auditor aparat inspektorat berpengaruh signifikan namun negatif terhadap kualitas auditor pada taraf signifikansi 5\% atau dengan kata lain H3 diterima.

\section{PENUTUP}

\section{Kesimpulan}

Berdasarkan hasil penelitian maka kesimpulan dari penelitian ini 
adalah Akuntabilitas auditor dan pengetahuan auditor berpengaruh positif dan signifikan terhadap kualitas hasil kerja auditor dan pengalaman auditor berpengaruh negatif namun signifikan terhadap kualitas hasil kerja auditor.

\section{Implikasi}

Penelitian ini dijadikan sebagai pembuktian empiris mengenai seberapa besar pengaruh faktor akuntabilitas, pengetahuan, pengalaman, terhadap kualitas hasil kerja auditor

\section{Keterbatasan dan Saran}

Evaluasi atas hasil penelitian ini harus mempertimbangkan keterbatasan yang mungkin mempengaruhi hasil penelitian, di antaranya adalah sulitnya mengendalikan responden. Penelitian selanjutnya dapat menggunakan metode lain atau setidaknya dapat memastikan pihak responden bersedia bekerja sama.

Saran untuk penelitian mendatang sebaiknya melakukan sebuah penelitian dengan menggunakan metode wawancara langsung untuk mengumpulkan data penelitian agar dapat melengkapi penelitian. Peneliti juga menyarankan untuk penelitian selanjutnya agar memperluas objek penelitian pada aparat inspektorat kabupaten/kota se-Provinsi Sulawesi Barat, sehingga hasilnya dapat digeneralisasi.

\section{DAFTAR PUSTAKA}

Abadi, J., \& Hidayat, W. (2011). Pengaruh Efektivitas Komite Audit, Komitmen Profesional, Tenure Of The Audit Firm, Dan Persaingan Antar Kantor Akuntan Publik Terhadap Independensi Akuntan Publik: Persepsi Auditor Eksternal Di Surabaya. Jurnal Akuntansi Dan Auditing, 8(1), 55-68.

Agoes, S. (2004). Auditing, Pemeriksaan Akuntan Oleh Kantor Akuntan Publik. Jakarta: LPFE-UI.

Agoes, Sukirno. (2018). Auditing: Petunjuk Praktis Pemeriksaan Akuntan Oleh Kantor Akuntan Publik,. Edisi 5 Jakarta: Salemba Empat

Alvita Tyas Dwi A. 2010. Pengaruh Nilai Personal Terhadap Sikap Akuntabilitas Sosial Dan Lingkungan. Tesis. Semarang: Universitas Diponegoro

Ardini, Lilis. 2010. Pengaruh Kompetensi, Independensi, Akuntabilitas Dan 
Motivasi Terhadap Kualitas Audit. Majalah Ekonomi Tahun XX, No. 3, Desember 2010: Hal 329-349.

Ariviana. Bella, 2014. Pengaruh Akuntabilitas, Pengetahuan, Pengalaman, Dan Independensi Terhadap Kualitas Kerja Auditor (Studi Empiris Pada Kantor Akuntan Pulik Di Kota Semarang Dan Surakarta) . Semarang: Surakarta.

Diani Mardisar Dan Ria Nelly Sari, 2007. Pengaruh Akuntabilitas

Pengetahuan Dan Pengalaman Terhadap Kualitas Hasil Kerja Auditor. Proceeding SNA X Makassar. AUEP-11.

Feny IImiyati Dan Yohanes Suhardjo. 2012. "Pengaruh Akuntabilitas Dan Kompetensi Auditor Terhadap Kualitas Audit(Studi Empiris Pada KAP Di Semarang)". Jurnal Akuntansi Vol. 1 No. 1 Januari 2012. Hal 46

Ghozali, I. 2018. Aplikasi Analisis Multivariat Dengan Program SPSS. Edisi 3. BP Undip. Semarang Goleman, D. 2008. Word.

Harhinto, Teguh. 2004. "Pengaruh Keahlian dan Independensi Terhadap Kualitas Audit Studi Empiris". Universias Diponegoro, Semarang.

Hidayat, M.T. 2011. Pengaruh Faktor -Faktor Akuntabilitas Auditor dan Profesionalisme Auditor Terhadap Kualitas Audit. Skripsi UNDIP. Semarang.

IAPI. 2011. Standar Profesional Akuntan Publik. Jakarta : Salemba Empat.

Indah, S. N., \& PAMUDJI, S. (2010). Pengaruh Kompetensi Dan Independensi Auditor Terhadap Kualitas Audit (Studi Empiris Pada Auditor Kap Di Semarang) (Doctoral Dissertation, Universitas Diponegoro).

IKAPI. 2008. Peraturan Menteri Keuangan Nomor 17 /PMK.01/2008 Jasa Akuntan Publik. Bandung : Fokusmedia.

Jensen, M and Mecking, W. 1976. Theory of The Firm: Managerial Behaviour, Agency Costs and Ownership Structure. Journal of financial Ecomomics 3 (4):305-360

Kuntadi, Cris. 2019. Audit Internal Sektor Publik. Jakarta Salemba Empat

Kurnia, P., Kennedy, K., \& Putri, F. P. (2015). Pengaruh Pengetahuan Auditor, Pengalaman Auditor, Kompleksitas Tugas, Locus Of Control, Dan Tekanan Ketaatan Terhadap Audit Judgment (Studi Kasus Pada Perwakilan BPKP Provinsi Riau)(Doctoral Dissertation, Riau University). 
Komite SPAP Ikatan Akuntan Indonesia (IAI), (2001), Standar Profesional Akuntan Publik. Jakarta : Salemba Empat.

Laksita, A. D., \& Sukirno, S. (2019). Pengaruh Independensi, Akuntabilitas, Dan Objektivitas Terhadap Kualitas Audit. Nominal, Barometer Riset Akuntansi Dan Manajemen, 8(1), 31-46.

Mansur, T. 2007. Faktor-Faktor yang Mempengaruhi Kualitas Audit Ditinjau dari Persepsi Auditor atas Pelatihan dan Keahlian, Independensi dan Penggunaan Kemahiran Profesional. Jurnal Magister Sains Akuntansi Universitas Gadjah Mada

Mahdi, S. A., \& Yetty, Y. (2019). Faktor-Faktor Yang Berpengaruh Terhadap Audit Judgment (Studi Pada Inspektorat Provinsi Maluku Utara). Hibualamo: Seri IImu-IImu Sosial Dan Kependidikan, 3(1), 4553.

Mardisar Dan Ria Nelly Sari.2007. Pengaruh Akuntabilitas Dan Pengetahuan Terhadap Kualitas Hasil Kerja Auditor. SNA. X.Universitas Riau

Praditaningrum S. Anugrah. 2012. Analisis Faktor-Faktor Yang Berpengaruh Terhadap Audit Judgment (Studi Pada BPK RI Perwakilan Provinsi Jawa Tengah). Skripsi. FE-UNDIP Semarang

Queena, P. P., \& Rohman, A. (2012). Analisis Faktor-Faktor Yang Mempengaruhi Kualitas Audit Aparat Inspektorat Kota/Kabupaten Di Jawa Tengah (Doctoral Dissertation, Fakultas Ekonomika Dan Bisnis).

Rahayu, T., \& Suryono, B. (2016). Pengaruh Independensi Auditor, Etika Auditor, Dan Pengalaman Auditor Terhadap Kualitas Audit. Jurnal IImu Dan Riset Akuntansi (JIRA), 5(4).

Sanjaya, K. S., Sujana, E., \& Herawati, N. T. (2019). Pengaruh Time Budget Pressure, Akuntabilitas, Dan Independensi Terhadap Kualitas Hasil Audit (Studi Empiris Pada 3 Kantor Inspektorat Di Provinsi Bali). JIMAT (Jurnal IImiah Mahasiswa Akuntansi) Undiksha, 10(1).

Sekaran, U. 2011. Research Methods For Business. Edisi 1 \& 2. Jakarta. Salemba Empat.

Sihombing, Y. A., \& Triyanto, D. N. (2019). Pengaruh Inependensi, Objektivitas, Pengetahuan, Pengalaman Kerja, Integritas Terhadap Kualitas Audit (Studi Pada Inspektorat Provinsi Jawa Barat Tahun 2018). 
Singgih, E. M., Bawono, I. R. (2010). Pengaruh Independensi, Pengalaman, Due Profesional Care Dan Akuntabilitas Terhadap Kualitas Audit. SNA XIII Universitas Jenderal Soedirman. Purwokerto.

Sucipto, Andre. 2007. Analisis Pengaruh Pengetahuan Dan Pengalaman Terhadap Kemampuan Akuntan Pemeriksa Dalam Mendeteksi Kekeliruan Pada KAP Di Surabaya. Surabaya : Bagian Penerbit Universitas Petra Surabaya

Sugioyono. 2013. Metodologi Penelitian Kuantitatif, Kualitatif Dan R\&D. Bandung. Alfabeta

Sugiarini, D. K., Diatmika, I. P. G., AK, S., Si, M., \& Edy Sujana, S. E. (2019). Analisis Pengaruh Pengalaman Kerja, Kompetensi, Dan Independensi Terhadap Kualitas Audit Internal Pada Inspektorat Kabupaten/Kota Di Provinsi Bali. JIMAT (Jurnal IImiah Mahasiswa Akuntansi) Undiksha, 10(2).

Suspayati, R. S., Djaddang, S., \& Darmansyah, D. (2019). Peran Akuntabilitas Dan Pengetahuan Terhadap Kualitas Hasil Audit Dengan Moderasi Sikap Mental Auditor. JIAFE (Jurnal IImiah Akuntansi Fakultas Ekonomi), 4(2), 171-188.

Zulkarmain, D. P., Cahyono, Y. T., \& MM, A. (2019). Pengaruh Integritas, Independensi Dan Pengalaman Auditor Terhadap Kualitas Audit (Studi Pada Kantor Inspektorat Di Karesidenan Surakarta) (Doctoral Dissertation, Universitas Muhammadiyah Surakarta). 